\title{
DEVELOPMENT OF THE WALKING MOVER FOR UNDERWATER WALKING VEHICLE
}

\author{
Vadim V. Chernyshev, Vladimir V. Arykantsev, Yaroslav V. Kalinin, \\ Andrey E. Gavrilov, Nikolay G. Sharonov
}

Volgograd State Technical University (VSTU), Lenin avenue, 28, Volgograd 400005, Russia

\begin{abstract}
Purpose of the work is to investigate possibility of practical application of walking machines for seabed movement. In particular, main tasks of investigation: tractional properties, passableness, methods of control. Technical features of walking machine "Vosminog" and underwater walking machine MAK-1, designed for shallow work, are noted in this paper. Advantages of walking machines in underwater conditions are described. Possibilities to improve adaptive characteristics and passableness of vehicle's cyclic walking locomotors are considered. Some of methods for motion control of underwater walking robot under conditions of incomplete and ambiguous understanding of the current situation are tested. Results of research and tests in real conditions of walking robots, which moves on sea bottom, are presented in the paper. It have shown that in underwater conditions walking type of mover for robots by roadhold properties and ground passableness essentially exceed traditional type of mover. Results of work can be demand during development of robotic systems, designed for advanced industrial technology for seabed resources mastering.
\end{abstract}

Keywords: Mobile robots; Underwater vehicles; Walking Mechanisms; Walking Robots; Robot Control; Robot Dynamics; Underwater Tests
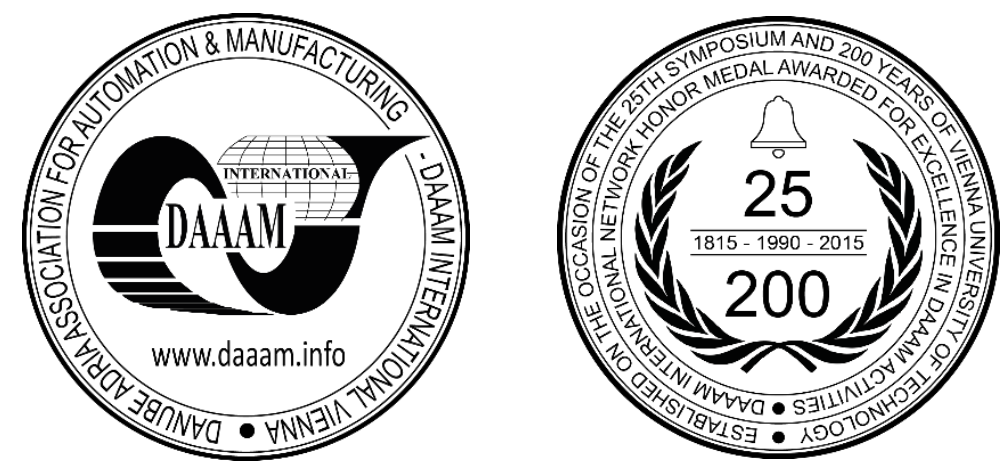

This Publication has to be referred as: Chernyshev, V[adim]; Arykantsev, V[ladimir]; Kalinin, Y[aroslav]; Gavrilov, A[ndrey] \& Sharonov, N [ikolay] (2016). Development of the walking mover for underwater walking vehicle, Proceedings of the 26th DAAAM International Symposium, pp.1143-1148, B. Katalinic (Ed.), Published by DAAAM International, ISBN 978-3-902734-07-5, ISSN 1726-9679, Vienna, Austria

DOI: $10.2507 / 26$ th.daaam.proceedings. 161 


\section{Introdution}

Investigation and industrial exploration of sea bottom resources without special technical equipment is impossible. Important role among machines for sea bottom exploration assigned to the autonomous ground devices which equipped with mining and geological prospecting working limbs as rippers, buckets, pickers, ground pumps etc. [1]. Practice of underwater engineering work is also sets some tasks, connected with holding of ground work (alignment of squares on the bottom, washing out of trenches and cables, closing them by soil, different kinds of archeological works under water etc.). That works are tiresome, it requires significant power of used machines and created by them tractional forces on the working instrument during the work. Wheeled and tracked vehicles are already being used as vehicles on the bottom [1-3]. However, exploitation conditions, which characterized by low-bearing capability of the soil and rough surface of the bottom, makes unusable the traditional types of movers. More suitable for using in conditions of sea bottom are walking movers, which have a better ground and shape passability [4-7]. Some experimental units of such walking machines are already known. For example, adaptive type underwater robots "CR200 Crabster" and "Ariel” [8, 9]. Real tests of this robots type confirmed their high passableness, but there is some problems with coordinated control of its legs [10-12]. Purpose of the work is to investigate possibility of practical application of walking machines for seabed movement. In particular, main tasks of investigation: tractional properties, passableness, control methods.

\section{Advantages of walking machines in underwater conditions}

Real tests confirms that walking machines in comparison with tracked and wheeled machines have more high ability on a soft ground and profile cross-country ability [4-7]. It is provided by high relative clearance of walking machine, discrete interaction of mover with ground and adaptation of foot to support surface. Cost reduction traction resistance movement also occurs [13]. The soil is not an obstacle for the movement for walking movement, unlike wheeled and tracked vehicles, but only requires the necessary expenses of power on soil pressing. Model of the forces acting on a wheeled or tracked and walking machines is shown in Fig. 1, where $F_{T}$ - traction going useful work; $F_{A}-$ adhesion force; $F_{G}$ - force of the resistance movement from the ground; $R_{\mathrm{W}}$-hydraulic resistance force.

a

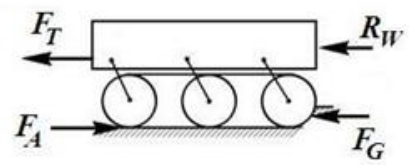

b

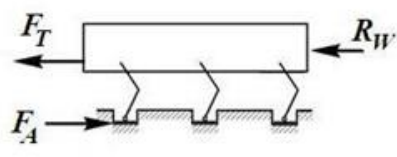

Fig. 1. Model of the forces acting on a wheeled or tracked (a) and walking machines (b)

As it seen from the model of forces for ground wheeled and tracked vehicles $F_{T}=F_{A}-F_{G}$. Adhesion force $F_{A}=k_{\varphi} N$ and the force of the resistance of movement from the ground $F_{G}=k_{f} N$ is proportional to the normal soil reaction $N$. For soils with a low bearing ability the ratio of coefficients of adhesion $k_{\varphi}$ and coefficients of resistance to movement $k_{f}$ such that even the tracked mover on similar soils does not allow to realize significant traction effort. The coefficient of adhesion on weak soils for tracked machines varies, usually within $k_{\varphi}=0.2-0.3$, and the coefficient $k_{f}=$ 0.1-0.2. In underwater environments, traction is reduced by virtue of the water resistance $R_{W}$. As tracked and wheeled machines have bad streamlined body, the force of resistance of the water commensurate with $F_{G}$ even at low speeds. Bottom currents may lead to increased resistance force $R_{W}$ many times. Also certain reserve traction is required in order to overcome biases. Thus, traditional vehicles can move under water only at the limit of adhesion.

Walking machines can provide on soils with a low bearing ability higher traction characteristics. Traction force (excluding water resistance) for walking machines is equal to the force of adhesion $F_{T}=F_{A}$ (Fig. $1 \mathrm{~b}$ ). In addition, the coefficient of adhesion for walking machines can be $\gg 1$. For example, if the feet are deep in the ground, then, obviously, you can implement significant horizontal thrust.

\section{Development of walking robots with cyclic type of movers}

Walking vehicles, which moves on sea bottom have to be simple and reliable. Such as walking ones with cyclic type of mover. Each mover consists of 2 paired walking mechanisms, cycle type, cinematically completely bound and work in antiphase $[14,15]$. In result at each moment at least one of walking mechanisms is in a contact with ground, thus, coefficient of the mode of this mover is equal to 1 . Using of cycle mover allows to don't care about walk save and stability and excludes necessity in controlled adapting system. In result, machines have minimal number of the controlled degree of freedom and becomes significantly simpler and cheaper of analogues with adaptive drive.

Several prototypes of walking machines were developed in VSTU. In particular, the 5-ton walking robot "Vosminog" (Fig. 2, a) was developed [14, 16]. Walking mechanisms are cycle (walking mechanisms of Umnov Chebyshev [17] have been used), on the base of 4-linked flat mechanisms with jointly fixed foots (Fig. 2, b). In forward movement mode, which different by biggest energy efficiency, height of the device step is comparably small. For shape 
passableness increasing in forward movement mode in walking device the system of passive adaptation of the foot to supporting surface has been realized. The supporting point trajectory of walking mechanism had been synthesized, it provides rising of toe of the foot in transferal phase at the expense for its kinematics and friction in foot joint, both during straight and reverse (back action) movement [14]. In a last case toe and heel exchanging their places in angle $\varphi 4$. Experimental studies to determine the traction characteristics walking machines on soft soil were carried out at its base. Part of the tests was conducted on submerged soils. Great nominal clearance of the walking robot allowed him to work at depths of up to $1.5 \mathrm{~m}$. Moreover, there is practical experience of using of the walking machines on bottom ground. Experimental tests have shown that walking machines with cyclic type of mover have extremely high ground passableness.In forward movement mode, which different by biggest energy efficiency, height of the device step is comparably small. Moreover, design of walking mover of cycle type of the robot «Vosminog» is not allow to change step parameters (height and length), significantly restrained abilities of passableness and cross-country capabilities. Also, high weight of the robot restrained his mobility during experiments in extreme conditions (in delivery to experiment place meaning). Therefore, in VSTU, modular hardware system has been developed, it intended for walking mechanism parameter optimization and development of energy efficient gait cycle of mobile robotic systems prototypes with walking mover.

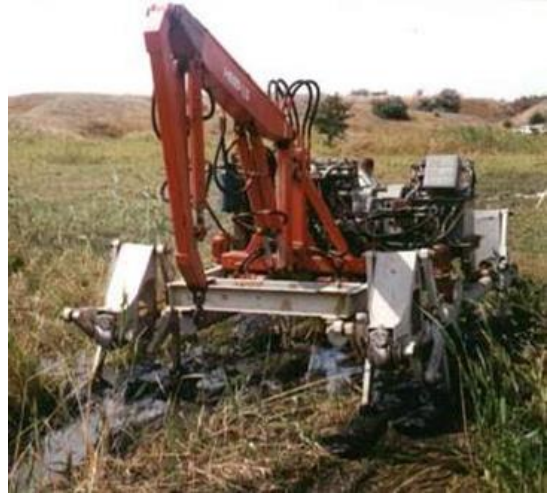

a

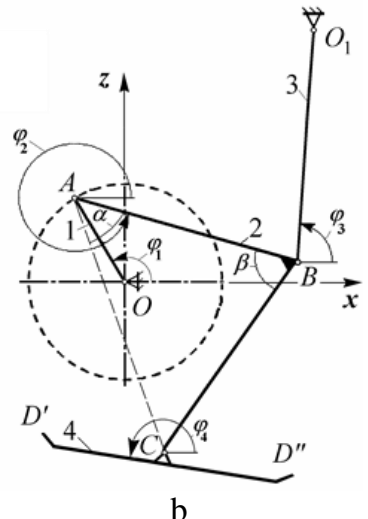

b

Fig. 2. Walking robot «Vosminog» (a) and his design scheme (b): 1 - cranks; 2 - curvilinear connecting rod; 3 rocking lever; 4 - foot.

On base of modular hardware system hexapod walking device MAK-1 was developed. This device can work with exchangeable equipment at small deeps. Constructively device includes completely bound walking limbs (walking modules) of right and left side (Fig. 3). Frame, which links walking limbs between ones, is modular. Its design can be changed in dependence of required additional equipment. Walking limbs are designed as bearing pieces, equipped with on-board power electrical drive with fixed walking mover on it. On-board electrical drives designed as separate power blocks (power modules), placed in water resistant boxes. Drive power executed via cable from external stand-alone power supply (gasoline power generator) or common power line. Total power of on-board drives is about $2 \mathrm{~kW}$. There is opportunity to smooth changing of velocity. Weight of the device is about $150 \mathrm{~kg}$. Maximum velocity under water is about $5 \mathrm{~km} / \mathrm{h}$. Device can work on deeps up to $20 \mathrm{~m}$. Modular technology, which used in MAK-1 device design, allows to easily upgrade it to special task.

Walking movers are cycle type with opportunity to adjust the trajectory of check points. Mover consists of 3 walking mechanisms (Fig. 4), cycle type, cinematically completely bound and work in antiphase (2 walking mechanisms works in in-phase, middle in counter-phase). Walking mechanisms are cycle, on the base of 5-linked flat mechanisms with jointly fixed foots (Fig. 4). Foots could be changed. It is possible to move without foots (the design of supporting points of walking mechanisms is adapted to interaction with ground).

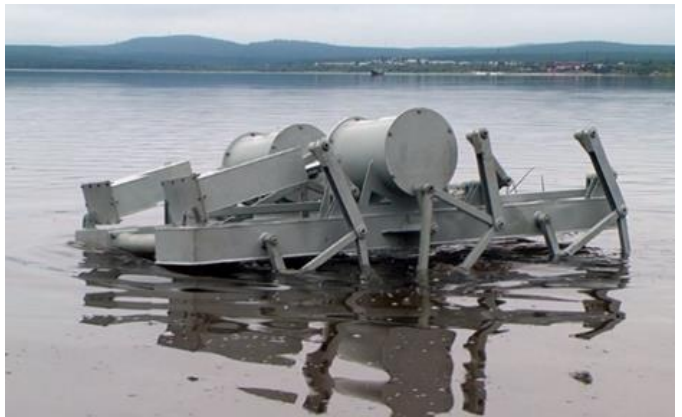

a

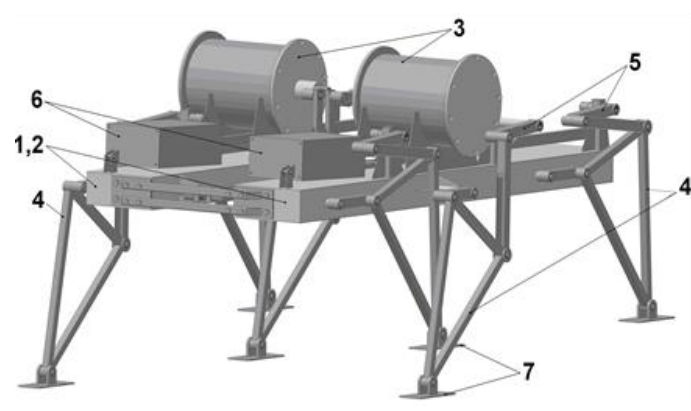

$\mathrm{b}$

Fig. 3. Underwater walking device MAK-1 (a) and his design scheme (b):1 — walking modules; 2 — bearing beam; 3 - on-board electrical drive in water resistant boxes; 4 - walking mechanisms; 5, 6 - suspension point mover mechanism and his linear electrical drive; 7 - foots 
Tests of experimental units of walking machines with cycle movers shows, that they are different by simplicity and reliability and can effectively work in extreme situations. With that, the modelling of the dynamics of typical cases of cycle walking machines movement shows, that for total realization of their abilities on shape passableness and maneuverability the ability to combine and adjust the programmed leg moves is necessary. For example, changing of step length before obstacle for better foot position providing, increasing of step high during salient obstacle passage, leg combining during turning for decreasing of the turning resistance moment etc.
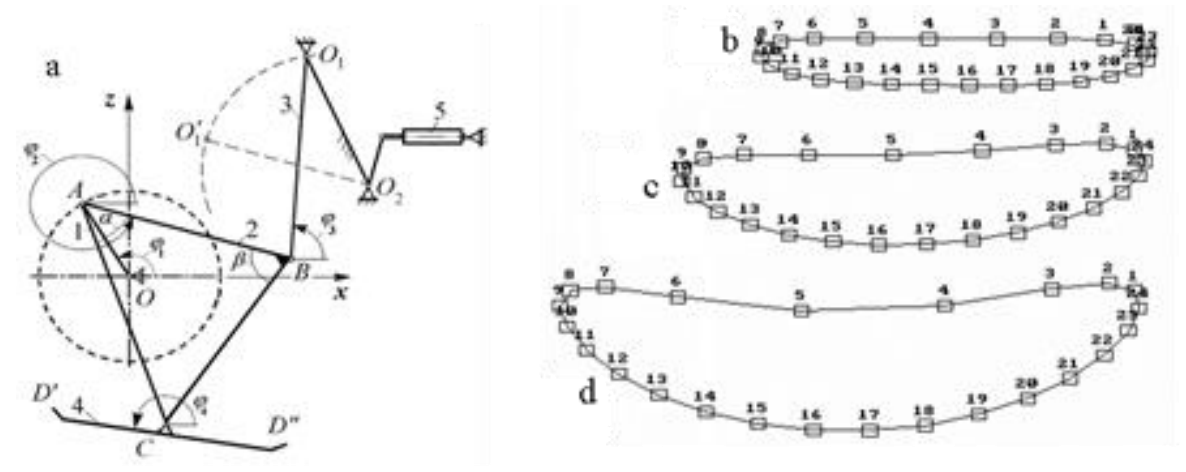

Fig. 4. Scheme of walking mechanism of the MAK-1 (a) and transformation of supporting point during movement (b, c, d): 1 - main winch; 2 - supporting link; 3 - arm; 4 - foot; 5 - linear electrical drive; O1O2 - con-trolled turning link of movement supporting point

In MAK-1 walking device the ability to combine and adjust the programmed leg moves has been achieved by introduction in walking mechanism of additional controlled degree of freedom as addition-al link (additional winch) with linear electrical drive (Fig. 4). Control of turning link brings to changing of its angular position (as gear shift in traditional vehicles). It brings to shifting of arm point of support of the walking mechanism and to transformation of forward movement base trajectory (Fig. 4 b) into obstacles passage mode with increased height and length of step (Fig. 4 c, d). Points on trajectories are set after equal periods of time $-1 / 24$ of full cycle. Lower branches of trajectories (points 11-22) are correspond to contact phase. At the same time walking mechanism is have one degree of freedom. Thereby control of relative supporting points trajectory is achieved (in quite wide range).

\section{Control of walking robot movement in underwater conditions}

One of the problems during work under water is limited visibility. Video sensors of the underwater robot are not allow to determine precisely parameters of an obstacle. Often an operator have no time to react and correct robot movement. Therefore motion performing in conditions of incomplete and ambiguous understanding of the current situation. In research process, some of methods of underwater walking device movement remote control are tested. Experience of walking machine control in rough terrain conditions, which executioners are have, shows, that operator not always can effectively to control all moves, and for visual control of each leg movement, for example, in process of obstacle passage, large video sensors quantity is necessary. Moreover, in our case it is impossible to have an operator right on the machine. That is why next way of movement control is assumed. Operator is not on the workspace and controls autonomously working machine on the visual information, transmitted from on-board video sensors and intervenes in movement control only if necessary. Task of movement control is solving without operator participating at low level of control (by on-board computer). At the same time there is no task of useful information determining by algorithms of picture processing in on-board video cameras signals to determine workspace characteristics, external conditions are assigned and shown on monitor display of operator as angle and angular speeds of jointly fixed foots, on positions of main winches and on amperage of on-board traction electrical drives and on some other parameters. In this case, the low level control system is not allows to find and truly determine the type and position of an obstacle - the control performs in partial and mixed information about a current situation. Therefore control failures are possible, when control given to high level (to the operator).

\section{Underwater walking device MAK-1 tests}

With the purpose to investigate design features influence of the walking mover on its roadhold properties, ground and cross-country passableness, maneuverability, controllability in underwater conditions, testing the MAK-1 walking device at small deeps have been held (Fig. 5). Dynamics of its supporting elements interaction with bottom ground have been investigated. During underwater tests was used the method [18], based on video recording of the walking device movement process with gradually increasing hook force with frame by frame processing of video on PC. Frame by frame processing consist in determining of marks position, which established on legs and body of walking device, relatively any natural landmark, which have been catch by frame. It allowed to determine the motion rule of the legs and body in relative and vertical direction, and on its values speed of foot slipping. 


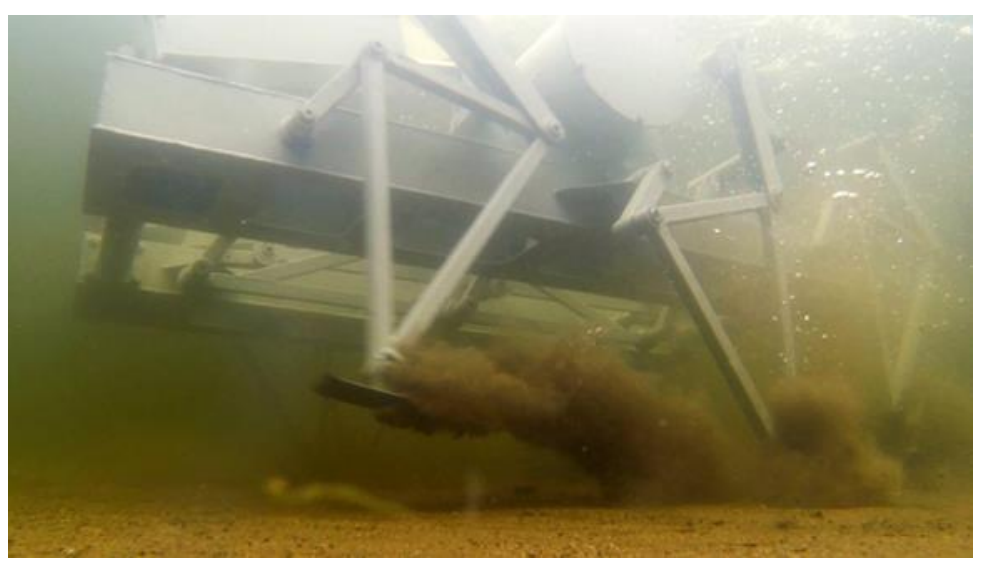

Fig. 5. Underwater walking device MAK-1 tests.

The tests have shown, that on relatively good grounds walking machines roadhold properties are exceed the same ones of wheel machines, it have small differences from track machines roadhold properties. Substantial advantage of the walking machines on traction properties could be catch only in very hard conditions, particularly, in underwater ground conditions. So on underwater grounds the walking machines adhesion coefficient was changed in dependence from ground properties, from 0,2 to the values, which could be compared with good properties ground $\left(k_{\varphi}=0,8-1,0\right)$, in some cases the $k_{\varphi}$ values was more than 1 . It confirms our model of forces. Best adhesion, as a rule, was during the substantial leg diving in the ground. With that, substantial influence of the grouser on roadhold properties had not been observed. In limited ground passability investigation were discovering conditions, when full loss of passability was observed, which connected with low bearing properties of the ground. For this purpose was realized movement on the most severe, from ground passability point of view, silty bottom areas. Held experiments also confirmed significant advantage of ground and shape passability comparing with traditional vehicles.

\section{Conclusion}

Held underwater tests shown, that walking machines on roadhold properties and ground passableness significantly better that track and wheel machines. Thus, in underwater ground conditions with low-bearing capacity walking movers, in compare with track and wheel, can provide better roadhold properties and increased ground passableness. Shape passableness of the walking machines is also better. It allow to increase energy efficiency of underwater works and as result decrease fuel expences of underwater vehicles, because ground is not an obstacle for walking machines, unlike for wheeled and tracked vehicles. Walking machines have low maximum velocity, but under water it doesn't matter. Therefore walking machines can be used in new industrial technologies of sea bottom resources exploration implementation.

\section{Acknowledgements}

The reported study was partially supported by RFBR, research projects No. 13-08-01144, 15-41-02451, 14 01 00655, 15-08-04166.

\section{References}

[1] S. Verichev, L. de Jonge, W. Boomsma, R. Norman, Deep mining: from exploration to exploitation // Minerals of the Ocean -7 \& Deep-Sea Minerals and Mining - 4: abstracts of International Conference / VNIIOkeangeologia. St. Petersburg, 2014, pp. 21-24.

[2] S. Hong, H.W. Kim, J.S. Choi, Transient Dynamic Analysis of Tracked Vehicles on Extremely Soft Cohesive soil, The 5th ISOPE Pacific/Asia Offshore Mechanics Symposium, 2002, pp. 100-107.

[3] H.W. Kim, S. Hong, J.S. Choi, Comparative Study on Tracked Vehicle Dynamics on Soft Soil: Single-Body Dynamics vs. Multi-body Dynamics, ISOPE, OMS-2003, Tsukuba, Japan, 2003, pp. 132-138.

[4] E.S. Briskin et al, On ground and profile practicability of multi-legged walking machines, Climbing and Walking Robots. CLAWAR 2001, Proc. of the 4-th Int. Conf. Karlsruhe, Germany, 2001. pp. 1005-1012.

[5] H.A. Warren, Mobile machines operating in outdoor unstructured terrains. In: Climbing and Walking Robots: Proceedings if the Fifth International Conference CLAWAR 2002. London, 2002, pp. 907-916.

[6] M.F. Silva, J.A.T. Machado, A literature review on the optimization of legged robots. Journal of Vibration and Control 18(12), pp. 1753-1767.

[7] V.E. Pavlovsky, A.K. Platonov, Cross-Country Capabilities of a Walking Robot: Geometrical, Kinematical and Dynamic Investigation, Theory and Practice of Robots and Manipulators, ROMANSY 13, Proc. of the 13-th CISMIFToMM Symposium, Zakopane, Poland, 2000, pp. 131138. 
[8] S.Y. Yoo, B.H. Jun, H. Shim, Design of static gait algorithm for hexapod subsea walking robot: Crabster, Transactions of the Korean Society of Mechanical Engineers, A, Volume 38, Issue 9, September 2014, pp. 989-997.

[9] G.A. Bekey, Autonomous Robots: From Biological Inspiration to Implementation and Control, 2005 , pp. 225.

[10] F. Šuligoj, B. Šekoranja, M. Švaco, B. Jerbić, B. Šekoranja, M. Švaco, B. Jerbić, Object Tracking with a Multiagent Robot System and a Stereo Vision Camera, 24th DAAAM International Symposium on Intelligent Manufacturing and Automation, 2013, pp. 965-973.

[11] S.C. Lim, G.H. Yeap, The Locomotion of Bipedal Walking Robot with Six Degree of Freedom, International Symposium on Robotics and Intelligent Sensors 2012 (IRIS 2012), Procedia Engineering, Volume 41, 2012, pp. 814.

[12] P. G. de Santos, E. Garoia, R. Ponticelli, and M. Armada, Minimizing Energy Consumption in Hexapod Robots, Advanced Robotics, vol. 23, pp. 681-704, 2009.

[13] V.V. Chernyshev, A.E. Gavrilov, Traction properties of walking machines on underwater soils with a low bearing ability // Minerals of the Ocean -7 \& Deep-Sea Minerals and Mining - 4: abstracts of Int. Conf. / VNIIOkeangeologia. - St. Petersburg, 2014, pp. 21-24.

[14] E.S. Briskin et al, The Investigation of Walking Machines with Movers on the Basis of Cycle Mechanisms of Walking, The 2009 IEEE International Conference on Mechatronics and Automation (Changchun, Jilin, August 912, 2009) : conf. proceedings.- [China], 2009, pp. 36313636.

[15] A. Comanescu, D. Comanescu, I. Dugaesescu, L.M. Ungureanu, Optimal Inverse Models For Bi-Mobile Mechanisms Of Walking Robot Legs, 24th DAAAM International Symposium on Intelligent Manufacturing and Automation, 2013, pp. 417-430.

[16] E.S. Briskin et al, On the energy efficiency of cyclic mechanisms, Mechanics of Solids, 2014, Vol. 49, No. 1, pp. 11-17.

[17] A.P. Bessonov, N.V. Umnov, V.V. Korenovsky, E.E. Silvestrov and S.V. Khoborkov, Six Link Mechanism for the Legs of Walking Machines, Theory and Practice of Robots and Manipulators. ROMANSY 13: Proc. of the 13-th CISM-IFToMM Symposium, International Centre for Mechanical Sciences, Wien: New York, 2000, pp. 347-354.

[18] V.V. Chernyshev et al, Modeling of the Dynamics of the Walking Machine with the Cyclic Propulsors as System Solids with Elastic and Damping Relations, The 3rd Joint International Conference on Multibody System Dynamics. The 7th Asian Conference on Multibody Dynamics, Busan (Korea), 2014. - 9 p. (pdf), http://imsdacmd2014.ksme.or.kr/. 